Article

\title{
Patterns of Intergroup Contact in Public Spaces: Micro-Ecology of Segregation in Australian Communities
}

Naomi Priest ${ }^{1, *}$, Yin Paradies ${ }^{2}$, Angeline Ferdinand ${ }^{3}$, Lobna Rouhani ${ }^{3}$ and Margaret Kelaher ${ }^{3}$

1 McCaughey Centre, Melbourne School of Population and Global Health, University of Melbourne, 5/207 Bouverie Street, Carlton, VIC 3010, Australia

2 Centre for Citizenship and Globalisation, Deakin Univeristy, Burwood Highway, Burwood, VIC 3125, Australia; E-Mail: yin.paradies@deakin.edu.au

3 Centre for Health Policy, Programs \& Economics, Melbourne School of Population and Global Health, University of Melbourne, 4/207 Bouverie Street Carlton, VIC 3010, Australia;

E-Mails: afer@unimelb.edu.au (A.F.); lobnarouhani@gmail.com (L.R.); mkelaher@unimelb.edu.au (M.K.)

* Author to whom correspondence should be addressed; E-Mail: npriest@unimelb.edu.au; Tel.: +61-3-8344-0926.

Received: 14 October 2013; in revised form: 3 December 2013 / Accepted: 20 December 2013 / Published: 7 January 2014

\begin{abstract}
The use of public spaces can promote social cohesion and facilitate interpersonal interactions within the community. However, the ways racial and ethnic groups interact in public spaces can also reflect and influence informal segregation in the wider community. The present study aimed to examine patterns of intergroup contact within public spaces in Victoria, Australia through short-term observation in four localities. Data were collected on within-group, intergroup and absence of contact for people from minority and majority groups. A total of 974 contacts were observed. Findings indicate that in the observed public spaces, people from visible minority groups tended to have no contact with others or to interact with people from other ethnic/racial groups. In contrast, those from the majority group tended to interact predominately with other majority group members. This suggests that majority group members are more likely to 'self-segregate' in public spaces than those from minority groups.
\end{abstract}

Keywords: intergroup contact; public space; segregation; Australia; observation; diversity 


\section{Introduction}

Across the world, factors such as globalization, natural disasters, political conflict, increasing urbanization and poverty have resulted in increased migration both within and between countries, permanently changing the social landscape. Recently, the populations of many high-income nations such as the United States, Canada, the United Kingdom, Australia and those in Western Europe have become increasingly ethnically, racially and culturally diverse through arrival of humanitarian and refugee entrants as well as skilled migrants [1,2]. These population movements, combined with existing histories of marginalization and exclusion of minority groups such as indigenous populations and those from African and Caribbean backgrounds has resulted in complex intercultural contexts and challenges related to multiculturalism and social cohesion [3].

At a national and community level, benefits of cultural diversity include increased productivity, creativity and wellbeing [4], with social cohesion and multiculturalism espoused within policies and practices in many contemporary societies [3]. Frequent and positive contact between those of different groups is also beneficial at an individual level, reducing prejudice and promoting positive intergroup relations [5,6]. Allport's seminal work identifying four conditions under which intergroup contact reduces prejudice remains highly influential, including the need for intimate rather than superficial interaction and a social environment supportive of prejudice reduction [5]. Building on this earlier work, a later meta-analysis of intergroup contact research found all four contact conditions may not in fact be required for prejudice reduction, with factors such as intergroup anxiety potentially playing a greater role in determining positive attitudinal changes [6]. Moreover, recent research indicates that negative contact has a more significant impact on increased prejudicial attitudes than positive contact has on reducing them [7].

Despite the benefits of positive intergroup contact and diversity across individual and community levels, in many contexts different groups live alongside each other with little interaction, resulting in contact that is illusory and cosmetic [8,9]. In this way the potential benefits of diversity and inclusion are compromised by informal segregation; a de facto system for regulating interaction between groups based on unofficial policies and practices that reproduce racial and ethnic barriers [10]. While some benefits of segregation have been identified within the empirical literature, including preservation of minority group identity and a buffering effect on health and wellbeing outcomes [11], the negative effects of segregation on society and individuals and its role in perpetuating racial/ethnic inequalities are persistently documented [12,13]. Most research examining the inter-connectedness between space and intergroup relations has been at a macro-spatial level using sociological and qualitative methods and focused on city or neighborhood residential segregation and its economic, social and political effects [9,14].

In many high-income countries, public spaces are often viewed as apparently neutral ground accessible and open to all; enabling people to interact with others within a wider community context, to meet in planned and unplanned ways, and through this facilitation of mixing to promote social cohesion [15]. The role of public spaces in promoting social inclusion and community cohesion, as well as supporting healthy lifestyles and emotional wellbeing, are increasingly prioritized within policy as well as research contexts [16]. However, concepts of "space" and "public" are both contested and open to interpretation [17-19], with social and physical environments highly interconnected, shaped 
via ongoing interactions [16,20]. Public spaces are frequently described as settings within which social networks and relationships are formed, maintained and shaped [16]. For example, Goffman's seminal work focused on the importance of fleeting, chance or momentary encounters [21] and Simmel described the sociological significance of minor social interaction in everyday settings [22-24]. Previous studies have explored the importance of public settings in providing opportunities for casual interactions and through this to building perceptions of inclusion and sense of community [25,26]. However, utilization of such public spaces varies considerably among individuals and different groups, with patterns of segregation and division at play [15]. Unequal power dynamics, positive and negative interactions, and division and cohesion, can all be features of public space [16,27-29]. As a result, the role of public spaces in promoting interethnic understanding and intergroup contact and in building community across diverse groups across is questioned and remains unclear [30,31].

Some suggest public spaces provide opportunity for interaction between different ethnic groups that would not otherwise occur in a more organized context, thus facilitating improved intergroup relations [16,30,32,33]. However, while spaces may be utilized by different ethnic groups, they may not necessarily interact nor is contact that does occur necessarily positive [16,32]. Instead of being sustained and meaningful, it is suggested that intergroup contact in public spaces is most likely to be fleeting or momentary [32]. Sennett takes this further and suggests interaction between groups of "others" in public is most likely to take one of three deficient modes: conflict, assimilation and indifference [34]. Others are more hopeful, highlighting the potential of public spaces to generate trust in urban diversity and acceptance of "throwntogetherness" [30,35]. In this context, there remains an ongoing need for more nuanced understandings and analysis of ways in which different social and cultural groups use public spaces, the degree to which spaces are shared and how shared spaces potentially influence community cohesion [16,30,36].

Beyond the theoretical and empirical research at the macro-spatial level described above, the micro-ecology of segregation within the everyday spaces of people's lives is also emerging as an important area of work $[9,10]$. This micro-ecology of segregation, and the everyday use of public spaces as sites in which informal segregation practices can be enacted and reproduced, is thus the focus of this paper. It is argued that the way in which routine or habitual practices are organized sociospatially function to uphold distance between groups and to reinforce dynamics of domination and subordination [14]. We examine these dynamics at an interpersonal micro level rather than the macro-spatial community or neighborhood level, building on the small but growing body of research focused on the micro-ecology of segregation.

To date, studies have empirically examined the micro-ecology of segregation within schools [37-39], universities [13,40,41], areas of open public seating [42], parks and playgrounds [43], shopping queues [44], bars and nightclubs [45], churches [46] and beaches [10]. These studies have been conducted in the United States, South Africa and the United Kingdom, with one study examining the use of space by children from refugee and non-refugee backgrounds in Australian primary schools [47,48].

Consistently across all these studies, the ongoing nature of segregation within everyday life spaces is documented. Ways in which segregation is reproduced and normalized via performative everyday practices within these spaces, and the norms imbued in such spaces that influence individual agency and behavior is also a common theme $[9,14,39]$. As others have noted, such informal everyday segregation practices within a given context are influenced by shared understandings about how groups 
do or do not interact [9]. Such informal segregation can also be considered an active process in which the meanings of shared space are negotiated among different groups, and thus not automatically the result of intergroup prejudice or poor intergroup relations $[9,14]$.

There remains an ongoing need for empirical data regarding the experiences and underlying processes of segregation, including ways in which prejudicial attitudes, experiences and behaviors may or may not have influence in these spaces. Moreover, given the highly contextual nature of intergroup relations and attitudes, as well as meanings and uses of space and place, there is a need for locally based studies to inform action to reduce segregation and to promote social cohesion and positive intergroup contact. Observational studies at a micro-ecological level provide opportunity to examine intergroup contact within everyday life spaces in a dynamic fashion, adding further depth to that provided by cross-sectional survey data examining experiences of discrimination or prejudicial attitudes, and to the macro-level sociological studies of neighborhoods and communities [14,49].

\section{Rationale and Aims}

The present study aimed to examine the micro-ecology of intergroup contact within public spaces in Victoria, Australia. It was designed to provide observational data as one component of a wider community baseline assessment for the evaluation of the Localities Embracing and Accepting Diversity (LEAD) program [50]. This study aimed to investigate the extent to which intergroup contact occurred as compared to within group or no contact between visible minority and majority racial/ethnic groups within public spaces. It also aimed to investigate key demographic and contextual characteristics influencing the nature of contact between visible minority and majority racial/ethnic groups in these public spaces. Thus, we hypothesized that intergroup contact between those from visible minority and majority backgrounds would be significantly rarer than no contact or within group contact across all public spaces.

\section{Methods}

\subsection{Study Setting}

Both LGAs involved in LEAD have high levels of cultural and linguistic diversity and low-medium average socio-economic status. LGA A is a large regional town situated approximately $200 \mathrm{~km}$ from Melbourne (population approximately 60,000) and LGA B is an outer suburban area of Melbourne (population approximately 155,000). The relative disadvantage of LGAs can be determined using the Socio-Economic Indexes for Areas (SEIFA). The SEIFA is used to compare how disadvantaged an area is in relation to other areas in Australia. The Victorian LGA ranked 1 is the most disadvantaged while the LGA ranked 79 is the most advantaged in the state. LGA A has a SEIFA ranking of 25 with $3.4 \%$ of its population identifying as Indigenous and 19.2\% born overseas [51,52]. LGA B has a SEIFA ranking of 42 , with $0.7 \%$ of its population identifying as Indigenous and $38.3 \%$ born overseas. The LEAD LGAs were not selected due to particularly high levels of racism or discriminatory behavior in comparison to other Victorian communities.

Ethics approval to conduct this study was received from Melbourne University Human Ethics Sub-Committee (HESC) on 3 March 2011. 


\subsection{Observation Methods}

Observations of within and intergroup contact between people of majority and minority backgrounds were conducted by one author (LR) in four public spaces in each of the LGAs following methods used previously [47]. The public spaces to be observed in each LGA were identified as locations of high use by people from both majority and minority cultural backgrounds by local government staff working within the LEAD program. In LGA A, this was the community library and sports center while in LGA B observations were conducted in a community library and a large shopping center.

Four two-hour observations were conducted in each setting across different time periods (morning, afternoon and evening) and days of the week (both weekdays and weekends) over a three-week period. In each location, the researcher identified peak times and places within the setting for observation in consultation with setting staff. In the LGA A library the areas observed were a computer area, children's area, newspaper/magazine section, and a television/gaming area on two mornings and two afternoons for three consecutive Thursdays and a Friday. For the sports center two indoor basketball courts and two netball courts were observed on two afternoons, one evening and one morning for three different weekdays (two consecutive Thursdays and one Wednesday). For the LGA B library observations were conducted in the newspaper area, children's area, and the computer space (divided into two sections due to its size) on two consecutive Saturday mornings and two weekday afternoons (Thursday and Friday). For the shopping center, two sections of a food court, an outdoor children's playground, and an indoor general seating area were observed on three weekday afternoons (two consecutive Thursdays and one Friday), one Thursday evening and one Sunday afternoon.

A map of each section was drawn for every visit and location and the activity of visitors was recorded. Each area was observed for 30 minutes. Date, time, visible racial/ethnic background (majority/minority), age range, type of contact (within, intergroup or none), group size and quality of contact (friendly/familial or conflict) were recorded every five minutes. Individuals were the unit of observation, with each individual present in each observation period given a unique ID number to allow for recording of type of contact as well as with whom contact was occurring, by recording ID numbers of others in the group. Group size was calculated by counting number of IDs. Contact rather than individual was the unit of analysis, as one individual may have more than one contact per five-minute period. Contact included verbal interaction, as well as non-verbal interaction while participating in or observing an activity such as a game, sporting match, eating a meal, or craft.

\subsection{Measures}

Outcome: Type of Contact.

Data on type of contact were coded in three categories: within group/intergroup/none.

Primary Explanatory Variable: Majority/minority group.

Participants were coded in two categories: majority (English-speaking White) and visible minority. Majority/minority group was researcher-assigned through observation of physical appearance (e.g., skin color), clothing (e.g., hijab, turban) and/or language use and linguistic cues. 


\section{Secondary Explanatory Variables:}

Other explanatory variables observed were gender; age coded in three groups for analysis (pre-teen, youth, adults); time of day coded in three groups (morning, afternoon, evening); setting (Library LGA A, Library LGA B, Sports Centre, Shopping Centre); length of interaction (less than 10 minutes, 10 minutes or more) and quality of interaction (friendly/familial, conflict).

\section{Statistical Analysis:}

Building on methods for quantitative analysis of space-use conducted previously [47], the following bivariate associations were examined separately for type of contact using simple multinomial regression with type of contact as the outcome and inter-group contact as the base category: majority/minority group, gender, age, time of day. Bivariate associations between type of contact (coded in two categories: within group and intergroup) as well as length of interaction were examined using simple logistic regression (length of interaction was not relevant when type of contact variable was “none”). Quality of interaction was not used in analysis due to low variance between categories with only $n=6$ interactions coded as conflict and the remaining familiar/familial. As the association between group size and type of contact was not significant at $p<0.1$, group size was not considered further in analysis.

Bivariate associations between length of interaction as the outcome and majority/minority group were examined in a separate model with logistic regression adjusted for clustering of participants by setting using robust standard errors. As this association was not significant at the $p<0.1$ level, further multivariable analysis using this outcome was not conducted. Bivariate association between this interaction variable as the outcome and majority/minority group were examined in a separate logistic regression model adjusted for clustering of participants by setting using robust standard errors. Stratified analysis of the bivariate relationship between length of interaction as the outcome and majority/minority group were also examined. This analysis utilized separate logistic regression models adjusted for clustering by setting using robust standard errors for within group and intergroup contact categories.

Multinomial regression with type of contact as the outcome and inter-group contact set as the base category was then undertaken. In the basic model, associations between type of contact and majority/minority group were examined. In the full model, gender, age, time of day were added. All models were adjusted for clustering of participants by setting using robust standard errors. Interaction between contact and other independent variables in the final model could not be explored due to sample size limitations and model instability.

\section{Results}

\subsection{Observations-Quantitative Analysis}

A total of 974 contacts were observed, with most occurring in the sports setting (40.7\%), followed by the shopping center (24.9\%) and libraries (13.0\% and 21.5\% in Library A and B respectively). Within group contact (69.4\% across the whole sample) was more commonly observed between 
individuals from majority (78.8\%) groups than among those from minority groups (46.5\%). For full detail of sample characteristics by contact type see Table 1.

Table 1. Sample characteristics by type of contact.

\begin{tabular}{|c|c|c|c|c|}
\hline & Total \% (n) & Within group \% (n) & Intergroup \% (n) & None \% (n) \\
\hline \multicolumn{5}{|l|}{ Setting } \\
\hline Library A & $13.0(127)$ & $25.2(32)$ & $11.8(15)$ & $63(80)$ \\
\hline Library B & 21.5 (209) & $49.8(104)$ & $13.4(28)$ & $36.8(77)$ \\
\hline Sports & $40.7(396)$ & $87.9(348)$ & $1(4)$ & $11.1(44)$ \\
\hline Shopping center & $24.9(242)$ & $79.3(192)$ & $4.6(11)$ & $16.1(39)$ \\
\hline \multicolumn{5}{|c|}{ Racial/ethnic background } \\
\hline Majority & $71.1(692)$ & $78.8(545)$ & $1.9(13)$ & $19.4(134)$ \\
\hline Visible minority & 29.0. (282) & $46.5(131)$ & $16.0(45)$ & $37.6(106)$ \\
\hline \multicolumn{5}{|l|}{ Gender } \\
\hline Male & $43.7(425)$ & $64.7(275)$ & $6.8(29)$ & $28.5(121)$ \\
\hline Female & $56.3(548)$ & $73.2(401)$ & $5.3(29)$ & $21.5(118)$ \\
\hline \multicolumn{5}{|l|}{ Age group } \\
\hline Pre-teens & $29.8(290)$ & $67.6(196)$ & $12.8(37)$ & $19.7(57)$ \\
\hline Youth & $5.7(55)$ & $65.5(36)$ & $5.5(3)$ & $29.1(16)$ \\
\hline Adults & $64.6(629)$ & $70.6(444)$ & $2.9(18)$ & $26.6(167)$ \\
\hline \multicolumn{5}{|l|}{ Time of day } \\
\hline Morning & 20.4 (199) & $58.8(117)$ & $2(4)$ & $39.2(78)$ \\
\hline Afternoon & $62.6(610)$ & $67.7(413)$ & $8.2(50)$ & $24.1(147)$ \\
\hline Evening & $16.9(165)$ & $88.5(146)$ & $2.4(4)$ & $9.1(15)$ \\
\hline \multicolumn{5}{|l|}{ Length of contact } \\
\hline$<10 \min$ & $36.8(272)$ & $84.2(229)$ & $15.8(43)$ & NA \\
\hline 10 min or more & $63.2(468)$ & $95.5(447)$ & $3.2(15)$ & NA \\
\hline Total & & $69.4(676)$ & $6.0(58)$ & $24.6(240)$ \\
\hline
\end{tabular}

At the bivariate level, significant associations were found between type of contact and majority/minority group, age group, gender, time of day, setting and length of interaction. For within group contact, significant associations $(p<0.05)$ were found with evening time period, and for adults. A marginally significant association $(p<0.10)$ was found for youth. For no contact, a significant association was found for youth, and a marginally significant association for adults. Type of contact was not significantly associated with gender or length of contact. People from visible minorities were significantly more likely to have intergroup contact rather than within group or no contact when compared to those from the majority group. Within group or no contact was more likely than intergroup contact in the morning and the evening rather than the afternoon. There was no difference between youth and pre-teens in the odds of having within group contact rather than intergroup contact. Youth were more likely than pre-teens to have no contact rather than intergroup contact. Adults were more likely than pre-teens to have within group rather than intergroup contact. However, the likelihood of having no contact rather than intergroup contact did not significantly differ among adults and pre-teens. See Table 2 for full detail of contact characteristics and bivariate analysis. 
Table 2. Bivariate relationships between type of contact, length of contact, and socio-demographic characteristics.

\begin{tabular}{|c|c|c|c|}
\hline & Type of contact & Unadjusted RRR & $P$ value \\
\hline \multicolumn{4}{|c|}{ Racial/ethnic background } \\
\hline & Within group & & \\
\hline \multirow[t]{2}{*}{ Visible minority } & & $0.07(0.02-0.23)$ & $<0.001$ \\
\hline & None & & \\
\hline Visible minority & & $0.23(0.1-0.54)$ & 0.001 \\
\hline \multicolumn{4}{|l|}{ Time of day } \\
\hline & Within group & & \\
\hline Morning & & $3.54(0.38-32.78)$ & 0.27 \\
\hline \multirow[t]{2}{*}{ Evening } & & $4.42(1-19.49)$ & 0.05 \\
\hline & None & & \\
\hline Morning & & $6.63(3.85-11.42)$ & $<0.001$ \\
\hline Evening & & $1.28(0.56-2.93)$ & 0.57 \\
\hline \multicolumn{4}{|l|}{ Gender } \\
\hline & Within group & $1.46(0.77-2.75)$ & 0.24 \\
\hline & None & $0.98(0.74-1.29)$ & 0.86 \\
\hline \multicolumn{4}{|l|}{ Age group } \\
\hline & Within group & & \\
\hline Youth & & $2.27(0.93-5.54)$ & 0.07 \\
\hline \multirow[t]{2}{*}{ Adults } & & $4.66(1.38-15.68)$ & 0.01 \\
\hline & None & & \\
\hline Youth & & $3.46(1.05-11.40)$ & 0.04 \\
\hline \multirow[t]{3}{*}{ Adults } & & $6.02(0.81-44.76)$ & 0.08 \\
\hline & & Unadjusted OR (95\% CI) & \\
\hline & Length of contact & & \\
\hline \multicolumn{4}{|l|}{ Type of contact } \\
\hline Within group & & $0.18(0.02-1.46)$ & 0.11 \\
\hline \multicolumn{4}{|c|}{ Racial/ethnic background } \\
\hline \multirow[t]{2}{*}{ Visible minority } & & $0.30(0.06-1.63)$ & 0.17 \\
\hline & Contact X length of contact & & \\
\hline \multicolumn{4}{|c|}{ Racial/ethnic background } \\
\hline Visible minority & & $9.23(2.07-41.03)$ & 0.003 \\
\hline
\end{tabular}

Base categories used: intergroup contact; majority; afternoon; male; pre-teens; RRR = Relative Risk Ratio.

Further exploration of the relationship between type of contact and all contact characteristics found that in the basic model, people identified as being from minority groups were significantly more likely to have within group or no contact than intergroup contact compared to those from majority backgrounds. People from minority backgrounds were more likely than people from majority backgrounds to have no contact. In the multivariable model, these associations remained significant when adjusting for gender, age group, setting and time of day. In the final model (Table 3), people from minority groups were less likely to have within group contact and more likely to have no contact than to have intergroup contact in comparison to those from majority backgrounds. 
Table 3. Multivariable adjusted associations between type of contact and socio-demographic characteristics.

\begin{tabular}{|c|c|c|c|c|}
\hline Type of contact & & $\begin{array}{c}\text { Unadjusted RRR } \\
(95 \% \mathrm{CI})\end{array}$ & Adjusted RRR (95\% CI) & $P$ value \\
\hline \multirow{9}{*}{ Within group } & Minority group & $0.07(0.02-0.22)$ & $0.10(0.02-0.57)$ & 0.01 \\
\hline & \multicolumn{4}{|l|}{ Gender } \\
\hline & Female & - & $0.89(0.56-1.43)$ & 0.64 \\
\hline & \multicolumn{4}{|l|}{ Age group } \\
\hline & Pre-teens/youth & - & $2.12(1.39-3.24)$ & 0.001 \\
\hline & Adults & - & $2.62(0.50-23.68)$ & 0.25 \\
\hline & \multicolumn{4}{|l|}{ Time of day } \\
\hline & Morning & - & $3.37(0.91-12.38)$ & 0.01 \\
\hline & Evening & - & $2.73(1.12-6.68)$ & 0.03 \\
\hline \multirow{9}{*}{ None } & Minority group & $0.23(0.10-0.54)$ & $0.40(0.16-1.02)$ & 0.05 \\
\hline & \multicolumn{4}{|l|}{ Gender } \\
\hline & Female & - & $0.63(0.39-1.03)$ & 0.07 \\
\hline & \multicolumn{4}{|l|}{ Age group } \\
\hline & Pre-teens/youth & - & $4.24(2.21-8.14)$ & $<0.001$ \\
\hline & Adults & - & $5.63(0.98-32.37)$ & 0.05 \\
\hline & \multicolumn{4}{|l|}{ Time of day } \\
\hline & Morning & - & $8.27(6.22-11.00)$ & $<0.001$ \\
\hline & Evening & - & $1.13(0.65-2.00)$ & 0.67 \\
\hline
\end{tabular}

Base categories: intergroup contact; majority; afternoon; male; pre-teens; RRR = relative risk ratio

\subsection{Observations-Field Notes}

Field notes from the observational data collection support the results of the quantitative analysis across all settings. Little intergroup contact, as well as minimal presence of community members from minority groups was observed in both shopping and sporting settings.

Less intergroup contact was observed at the shopping mall where a majority of patrons were of an Anglo background. All interactions observed were between family members or friends with the exception of one intergroup interaction between two members of the cleaning staff and a couple of intergroup interactions in the children's playground which were perceived as positive. (Observational field notes LGA B 19/5/2011 5:00 p.m.-5:25 p.m.)

In contrast, although observations suggested that libraries were generally a positive space for community members from minority groups, and that they were happy to spend time there socializing and using the facilities, there was still minimal intergroup contact observed.

...the library was not only being used for browsing, reading, and learning, but also a social space as well.... speaking in languages other than English (Greek, Hindi and local African languages). (Observational field notes LGA B 26/5/2011 11:00 a.m.-12:55 p.m.)

One group of male children use the space to play cards, their interaction is friendly. A group of Middle Eastern Muslim women and their children sit on the floor talking and taking pictures of each other. Perhaps 
this demonstrates they are feeling safe and comfortable in this particular public space? A number of others used this section to read with family or to play with family and friends. (Observational field notes LGA B 15/5/2011 3:30 p.m.-3:55 p.m.)

On two separate days a group of young group of Afghani males were present...perhaps this is a space they frequent often to socialize and use the game resources. The weekly knitting group comprised individuals from diverse cultural backgrounds who also use this space, and positively interact with each other. (Observational field notes LGA A 17/6/2011 10:30 a.m.-10:45 a.m.)

In the computer area there was one intergroup interaction and slight altercation between an Anglo male and Middle Eastern male whereby the Middle Eastern male stood behind the Anglo male’s computer watching the screen making the Anglo male uncomfortable and leading him to ask the Middle Eastern male to 'go away’. (Observational field notes LGA A 21/5/2011 3:55 p.m.-4:00 p.m.)

\section{Discussions}

The main findings from this observational study indicate that in public spaces within two localities in Victoria, Australia people from visible minority groups tend to have no contact with others or to interact with people from their own or other visible minority ethnic/racial groups while those from the majority group (Anglo/White Australians) tend to interact predominately with others from their own ethnic/racial group. To our knowledge, this study is the first to find that people are more likely to have intergroup contact in the afternoon compared to the morning or evening. Possibly this is due to the public spaces in this study being busier during the afternoon as students finish school and along with their caregivers frequent public spaces; thus, providing more opportunity for intergroup contact. However, this possible explanation does not fully explain the finding as nearly $40 \%$ of contacts observed in this study were not in the afternoon, with relatively similar proportions of these in the morning and the evening. Further research is required on the factors resulting in this temporal cycle of intergroup sociality which may have implications for scheduling large-scale public events aimed at "community building” [53].

This finding suggests that majority group members are more likely to "self-segregate" in public spaces than those from minority groups, supporting evidence from macro-level studies that "generally the preferences of the majority will have a stronger impact on segregation patterns" that those of the minority [54]. This study also indicates that minority people are likely to be socially isolated (i.e., no contact) when majority group members self-segregate. More generally, qualitative field notes suggest minimal presence of community members from minority groups in public spaces, despite the fact that $19.2 \%$ and $38.3 \%$ of residents in LGA A and B, respectively, were born overseas. As such, the main finding of this study could reflect an under-representation of those from minority groups in public spaces such that the contact options for minority people are predominantly an absence of contact or intergroup contact.

Evidence from surveys examining experiences of racism and associated responses and health effects among minority group members in these communities indicate that $17 \%$ experience racism at least nine times a year and $24 \%$ avoid specific situations because of racism often or very often [55,56]. As supported in Australian qualitative research in which respondents reported staying home more 
often as well as avoiding public transport and shopping [57], this may be a contributing factor to such under-representation. As noted by Noble and Poynting, experiences of racism can "limit the citizen-rights of the targeted to be in a given place” [57].

As noted in the introduction, informal segregation can result from negotiation among different groups about the meanings of shared space, and thus is not necessarily the result of intergroup prejudice or poor intergroup relations [9,14]. However, regardless of its causes, we concur with Noble and Poynting that "thwarting of socio-spatial engagements" compromises "effective citizenship [which] requires access to and comfort in a multitude of spaces" while also stunting "capacities to forge networks of co-operation" [57] vital to social inclusion and cohesion.

A recent review of eight Australian studies indicate that although positive intergroup contact does not always lead to reduced prejudice, negative intergroup contact strongly predicted increased prejudice [7]. As such, it is important to note that intergroup interactions observed in this study were almost exclusively positive, that is observed to be familiar/familial and without observable signs of conflict. Moreover, the length of interaction did not significantly differ between intragroup and intergroup contact, suggesting a similar level of contact quality for intra and intergroup interactions. While avoiding "exaggerated claims... that more interaction in the form of... contrived meetings will necessarily nurture intercultural engagement and understanding” [58], there appears to be some potential for improving intergroup relations through increased intergroup contact in Australian public spaces. One avenue to achieving this would be to promote the required social norms via national government strategies, such as the National Anti-Racism Strategy 'Racism. It Stops with me' campaign [59] informed by current anti-racist scholarship [60,61].

The study shows the potential for observational methods to provide information that can inform interventions over and above what can be learned from survey methods or qualitative data collection. High reported exposures to racism in public places among minority groups co-occurred with a tendency for majority groups to self-segregate in the same settings. While it is plausible the size of the minority group influences the likelihood of intra- and inter- group contact, in this study the relatively large sample of the minority group (30\%) makes this unlikely. Refinement of methods was not possible in this study here due to resource limitations, but would be useful to further advance knowledge in this area. For example, inter-rater reliability through use of more than one observer to collect data, as well as more detailed ethnographic and field observational data regarding nature of interactions beyond whether they were inter- or intra- group. It is also important to acknowledge that the observational nature of the study meant that attribution of race/ethnicity was determined by authors' perceptions of visible differences and potentially influenced by social norms of difference. Asking participants to report their own race/ethnicity was not appropriate for the observational nature of this study. This study demonstrates the value of using different methodological approaches to inform intervention design, including those using observational methods rather than solely relying on self-report. The findings of this study highlight an important behavioral target for intervention to reduce racism and provide specific and contextual information regarding interactions within public settings. In particular, targeting public spaces as settings for intergroup contact as well as to promote accessibility and use by those from minority backgrounds may be a key strategy for reducing racism and promoting cultural diversity. 


\section{Acknowledgments}

The LEAD program is funded by the Victorian Health Promotion Foundation (VicHealth), the Department of Immigration and Citizenship (DIAC) through its Diverse Australia program and beyondblue, Australia's peak body for mental health issues. The current research was carried out as part of the LEAD program. The authors are part of the LEAD evaluation team. Naomi Priest is supported by an NHRMC Post Doctoral Fellowship and by the Victorian Health Promotion Foundation. Margaret Kelaher was supported by an ARC Future Fellowship.

\section{Conflicts of Interest}

The authors declare no conflict of interest

\section{References}

1. Australian Bureau of Statistics (ABS). 2006 Census of Population and Housing; ABS: Canberra, Austrilia, 2007.

2. United Nations Development Program. Human Development Report 2002: Deepening Democracy in a Fragmented World; Oxford University Press: New York, NY, USA, 2002.

3. Hage, G. Analysing Multiculturalism Today. In The Sage Handbook of Cultural Analysis; Bennett, T., Frow, J., Eds.; SAGE Publications Ltd.: Los Angeles, CA, USA, London, UK, 2008.

4. Page, S. The Difference: How the Power of Diversity Creates Better Groups, Firms, Schools and Societies; Princeton University Press: Princeton, NJ, USA, 2007.

5. Allport, G. The Nature of Prejudice; Addison-Wesley: Reading, MA, USA, 1954.

6. Tropp, L.R.; Pettigrew, T.F. Differential relationships between intergroup contact and affective and cognitive dimensions of prejudice. Pers. Soc. Psychol. Bull. 2006, 31, 1145-1158.

7. Barlow, F.K.; Paolini, S.; Pedersen, A.; Hornsey, M.J.; Radke, H.R.M.; Harwood, J.; Sibley, C.G. The contact caveat: Negative contact predicts increased prejudice more than positive contact predicts reduced prejudice. Pers. Soc. Psychol. Bull. 2012, 38, 1629-1643.

8. Taylor, D.M.; Moghaddam, F.M. Theories of Intergroup Realtions: Internal Social Psychological Perspectives; Praeger: London, UK, 1994.

9. Alexander, L.; Tredoux, C. The spaces between us: A spatial analysis of informal segregation at a south african university. J. Soc. Issues 2010, 66, 367-386.

10. Dixon, J.; Durrheim, K. Contact and the ecology of racial division: Some varieties of informal segregation. Br. J. Soc. Psychol. 2003, 42, 1-23.

11. Kramer, M.R.; Hogue, C.R. Is segregation bad for your health? Epidemiol. Rev. 2009, 31, 178-194.

12. Viruell-Fuentes, E.A.; Miranda, P.Y.; Abdulrahim, S. More than culture: Structural racism, intersectionality theory, and immigrant health. Soc. Sci. Med. 2012, 75, 2099-2106.

13. Clack, B.; Dixon, J.; Tredoux, C. Eating together apart: Patterns of segregation in a multi-ethnic cafeteria. J. Community. Appl. Soc. Psychol. 2005, 15, 1-16.

14. Dixon, J.; Tredoux, C.; Clack, B. On the micro-ecology of racial division: A neglected dimension of segregation. S. Afr. J. Psychol. 2005, 35, 395-411. 
15. Holland, C.; Clark, A.; Katz, J.; Peace, S. Social Interactions in Urban Public Places; The Policy Press: Bristol, UK, 2007; Volume 2: Joseph Rowntree Foundation.

16. Cattell, V.; Dines, N.; Gesler, W.; Curtis, S. Mingling, observing, and lingering: Everyday public spaces and their implications for well-being and social relations. Health Place 2008, 14, 544-561.

17. Sennett, R. The Fall of the Public Man; Norton: New York, NY, USA, 1974.

18. Habermas, J. The Structural Transformation of the Public Sphere; Polity Press: Cambridge, UK, 1989.

19. Goheen, P. Public space and the geography of the modern city. Prog. Hum. Geog. 1998, 22, 479-496.

20. Yen, I.H.; Syme, S.L. The social environment and health: A discussion of the epidemiologic literature. Annu. Rev. Public Health 1999, 20, 287-308.

21. Goffman, E. Stigma: Notes on the Management of Spoiled Identity; Prentice Hall: Englewood Cliffs, NJ, USA, 1963.

22. Goffman, E. Behaviour in Public Places; Free Press: New York, NY, USA, 1963.

23. Featherstone, M. Georg simmel: An introduction. Theor. Cult. Soc. 1991, 8, 1-16.

24. Lecher, F.J. Simmel on social space. Theor. Cult. Soc. 1991, 8, 195-201.

25. Cattell, V.; Evans, M. Neighbourhood Images in East London; Joseph Rowntree Foundation/York Publishing Services: York, UK, 1999.

26. Cattell, V.; Herring, R. Social capital and well being: Generations in an east london neighbourhood. J. Mental. Health. Prom. 2002, 1, 8-19.

27. Brewer, J.D. The public and private in C. Wright Mill's life and work. Sociology 2005, 39, 661-677.

28. Bridge, G.; Watson, S. Lest power be forgotten: Networks, division and difference in the city. Soc. Rev. 2002, 50, 505-518.

29. Keith, M. After The Cosmopolitan: Multicultural Cities and the Future of Racism; Routledge: London, UK, New York, NY, USA, 2005.

30. Lownsbrough, H.; Beunderman, J. Equally Spaced? Public Space and Interaction between Diverse Communities: A Report for the Commission for Racial Equality; Demos: London, UK, 2007.

31. Amin, A. Ethnicity and the Multicultural City: Living with Diversity; Report for the Department of Transport, Local Government and the Regions and ESRC Cities Initiative; DRLR: London, UK, 2002. Available online: http:/storage.globalcitizen.net/data/topic/knowledge/uploads/ 20121009135144462048_Amin_ethnicity-2.pdf (accessed on 12 November 2013).

32. Vertovec, S. New Complexities of Cohesion in Britain: Super-Diversity, Transnationalism and Civil-Integration ESRC Centre on Migration; Policy and Society: Oxford, UK, 2007.

33. Dines, N.; Cattell, V. Public Spaces, Social Relations and Well-Being; The Policy Press: Bristol, UK, 2006.

34. Sennett, R. Civility. Available online: http://www.richardsennett.com/ (accessed on 20 July 2013).

35. Amin, A. Thinking Past Integration and Community Cohesion. In Procedings of the COMPAS Annual Conference, Oxford University, Oxford, UK, 5-6 July 2007.

36. Williams, K.; Green, S. Literature Review of Public Space and Local Environments for the Cross Cutting Review; Oxford Brooks University: Oxford, UK, 2001.

37. McCauley, C.; Plummer, M.; Moskalenko, S.; Mordkoff, J.T. The exposure index: A measure of intergroup contact. Peace Confl. 2001, 7, 321-336. 
38. Schofield, J.W.; Sagar, H.A. Peer interactioin patterns in an integrated middle school. Sociometry 1977, 40, 130-138.

39. Thomas, M.E. "I think it's just natural”: The spatiality of racial segregation at a us high school. Environ. Plann. 2005, 37, 1233-1248.

40. Schrieff, L.; Tredoux, C.; Dixon, J.; Finchilescu, G. Patterns of racial segregation in university residence dining-halls. S. Afr. J. Psychol. 2005, 35, 433-443.

41. Koen, J.; Durrheim, K. A naturalistic observational study of informal segregation: Seating patterns in lectures. Environ. Behav. 2009, 42, 448-468.

42. Tredoux, C.; Dixon, J.; Underwood, S.; Nunez, D.; Finchilescu, G. Preserving spatial and temporal dimensions in observational data of segregation. S. Afr. J. Psychol. 2005, 35, 412-432.

43. Loukaitou-Sideris, A. Children's common grounds: A study of intergroup relations among children in public settings. J. Am. Plann. Assoc. 2003, 69, 130-145.

44. Kaplan, P.F.; Fugate, D. Pilot study of racial interaction in public place: Northern and southern settings compared. Int. J. Group Tensions 1972, 2, 63-72.

45. Tredoux, C.G.; Dixon, J.A. Mapping the multiple contexts of racial isolation: The case of long street, cape town. Urban Stud. 2009, 46, 761-777.

46. Parker, J.H. The interaction of negroes and whites in an integrated church setting. Soc. Forces 1968, 46, 359-366.

47. Due, C.; Riggs, D.W. Playing at the edges: Use of playground spaces in south australian primary schools with new arrivals programmes. Soc. Geogr. Discuss. 2010, 6, 1-38.

48. Due, C.; Riggs, D. Freedom to roam? Use of schoolyard space in primary schools with new arrivals programs. Int. Res. Early Child Educ. 2011, 2, 1-16.

49. McKeown, S.; Cairns, E.; Stringer, M. Is shared space really shared? Shared Space 2012, 83-94.

50. Ferdinand, A.; Kelaher, M.; Paradies, Y. The role of effective partnerships in an australian place-based intervention to reduce race-based discrimination. Public Health Rep. 2013, 128, 54-60.

51. Australian Bureau of Statistics (ABS). Census of Population and Housing: Socio-Economic Indexes for Areas (Seifa), Australia; ABS: Canberra, Australia, 2006.

52. Australian Bureau of Statistics (ABS). 2011 Census Community Profiles; ABS: Canberra, Australia, 2011.

53. Richardson, T.A. At the garden gate: Community building through food: Revisiting the critique of “food, folk and fun” in multicultural education. Urban Rev.2011, 43, 107-123.

54. Koopmans, R. Trade-offs between equality and difference: Immigrant integration, multiculturalism and the welfare state in cross-national perspective. J. Ethnic Migrat. Stud. 2010, $36,1-26$.

55. Ferdinand, A.; Paradies, Y.; Kelaher, M. Mental Health Impacts of Racial Discrimination in Victorian Aboriginal Communities; VicHealth: Melbourne, Australia, 2012. Available online: http://www.vichealth.vic.gov.au/ /media/ResourceCentre/PublicationsandResources/Discrimination/ Mental\%20health\%20impacts_racial\%20discrim_Indigenous.ashx (accessed on 12 November 2013).

56. Ferdinand, A.; Paradies, Y.; Kelaher, M. Mental Health Impacts of Racial Discrimination in Victorian Culturally and Linguistically Diverse Communities; VicHealth: Melbourne, Australia, 2012. Available online: http://www.vichealth.vic.gov.au/ /media/ResourceCentre/Publications 
andResources/Discrimination/VH_Racial\%20Discriminiation_CALD_web.ashx (accessed on 12 November 2013).

57. Noble, G.; Poynting, S. White lines: The intercultural politics of everyday movement in social spaces. J. Intercult. Stud. 2010, 31, 489-505.

58. Swanton, D. Sorting bodies: Race, affect, and everyday multiculture in a mill town in northern england. Environ. Plann. 2010, 42, 2332-2350.

59. Australian Human Rights Commission. National anti-racism strategy: Consultation report. Available online: http:/itstopswithme.humanrights.gov.au/sites/itstopswithme.humanrights.gov.au/ files/consultation_report.pdf (accessed 3 April 2013).

60. Paradies, Y.; Chandrakumar, L.; Klocker, N.; Frere, M.; Webster, K.; Burrell, M.; McLean, P. Building on Our Strengths: A Framework to Reduce Race-Based Discrimination and Support Diversity in vicToria; Full Report; Victorian Health Promotion Foundation: Melbourne, Australia, 2009.

61. Pedersen, A.; Walker, I.; Paradies, Y.; Guerin, B. How to cook rice: A review of ingredients for teaching anti-prejudice. Aust. Psychol. 2011, 46, 55-63.

(C) 2014 by the authors; licensee MDPI, Basel, Switzerland. This article is an open access article distributed under the terms and conditions of the Creative Commons Attribution license (http://creativecommons.org/licenses/by/3.0/). 